\title{
MADRID Y ROMA EN LA SEGUNDA MITAD DEL SIGLO XVIII. LA LUCHA CONTRA LAS «USURPACIONES» ROMANAS
}

\author{
Maximiliano BARRIO GOZALO \\ Universidad de Valladolid
}

\begin{abstract}
Resumen
Por medio del estudio de la correspondencia confidencial del Secretario de Estado de Nápoles, Bernardo Tanucci, con los ministros españoles Ricardo Wall y Jerónimo Grimaldi, entre 1759 y 1776 , se analizan los planteamientos regalistas de los ministros de la Casa de Borbón, basados en la defensa de la jurisdicción episcopal y los ideales de la Iglesia primitiva, y opuestos a los de la Curia romana y a los de la Compañía de Jesús.
\end{abstract}

\begin{abstract}
Through the confidential correspondence study of the State Secretary of Nápoles, Bernardo Tanucci with the Spanish ministers Ricardo Wall and Jerónimo Grimaldi -between 1759 and 1776-, the defence of the royal prerogatives is analyzed in the House of Bourbon ministers, based on the defense of the episcopal jurisdiction and the ideals of the primitive Church, and opposed to the Roman Curia and those of Jesuits.
\end{abstract}

En la correspondencia confidencial que mantiene semanalmente Bernardo Tanucci, Secretario de Estado de las Dos Sicilias ${ }^{1}$, con su homónimo de España, Ricardo Wall (1759-1763) y, cuando éste cesa ${ }^{2}$, con Jerónimo Grimaldi (1763-1776) ${ }^{3}$, ad-

1. La obra que todavía hoy traza el retrato más completo e informado de Tanucci, aunque en algunos aspectos haya sido superada por las nuevas aportaciones historiográficas, es la de VIVIANI DELLA ROBBIA, E. Bernardo Tanucci e il suo piú importante carteggio, I: Biografia, Firenze 1942. La numerosa bibliografía tanucciana, en cuanto se refiere al estudio de su persona y de su acción política, ha sido reunida por Mario D'ADDIO, en la «Prefazione» a Bernardo Tanucci. Epistolario, I (1723-1746), Roma 1980; pp. LXXIX-LXXX. Al amplio elenco que ofrece Mario D'Addio hay que añadir los múltiples estudios publicados posteriomente y, en concreto, las Actas de los dos congresos que se celebraron en torno a su figura en el segundo centenario de su muerte: Bernardo Tanucci..Statista. Letterato. Giurista. Atti del Convegno Internationale di studi per il secondo centenario (1783-1983), Napoli 1986, 2 vols.; y Bernardo Tanucci e la Toscana. Tre giorni di studio, Firenze 1986.

2. Cuando el marqués de la Ensenada cae en desgracia (1757), Ricardo Wall pasa a ocupar la Secretaría de Estado, desempeñando este oficio hasta septiembre de 1763, en que dimite «por los molestos efectos de 
quiere gran importancia la temática eclesiástica ${ }^{4}$, según he podido comprobar y ratifica el mismo Grimaldi con estas palabras:

"Los asuntos eclesiásticos, que llenan la mayor parte de nuestra correspondencia, le son a V.E. tan familiares que no le ha de costar mucho trabajo el escribir y razonar sobre ellos. Yo, al contrario, estoy ignorante de estas materias. Nunca las he considerado sino por el lado que tienen relación con la política y, por esta razón, confieso a V.E. que no tengo más noticia de la curia romana que la del daño que nos hace »s.

La información que aporta este epistolario ofrece abundantes datos para conocer algunos aspectos de la lucha que España mantiene en el siglo XVIII contra la «usurpadora» Roma y los regulares, sus mejores valedores, a fin de «reformar» la Iglesia y hacerla más nacional, tema sobre el que versarán las siguientes páginas, circunscritas al pontificado de Clemente XIII 1758-1769) ${ }^{6}$.

Ahora bien, para situar en su contexto histórico las afirmaciones de Tanucci, Wall y Grimaldi hay que tener en cuenta, por una parte, los nuevos matices del regalismo español y del anticurialismo, y por otra, el anhelo de los ilustrados por retornar al modelo idealizado de la Iglesia primitiva, despojada de los abusos e idealizada con el ejercicio pleno de la jurisdicción episcopal, no limitada por las «reservas romanas» ni por las exenciones de los frailes, que limitaban los derechos de los obispos ${ }^{7}$. Por ello, antes de presentar las ideas que estos políticos regalistas vierten en su correspondencia, diré unas palabras sobre la defensa de las regalías.

\section{LA DEFENSA DE LAS REGALÍAS}

El regalismo del siglo XVIII, a diferencia del siglo anterior, no apoya el derecho del monarca a intervenir en los asuntos eclesiásticos en la concesión pontificia, sino que concibe la regalía como un derecho mayestático, inherente a la soberanía regia.

la vejez y por la decadencia que experimenta en la vista» (AGS, Estado, leg. 6094: Wall a Tanucci. San Ildefonso 23 agosto 1763), aunque Ja verdadera razón parece que fue la derogación de la pragmática del exequatur por Carlos III sin haberle consultado. Cfr. RODRIGUEZ CASADO, V., La política y los políticos en el reinado de Carlos III, Madrid 1962, pp. 92-93.

3. Tras la dimisión de Wall, le sucede en la Secretaría de Estado y ejerce el cargo hasta el año 1776, en que cesa y pasa a ocupar la embajada de España en Roma. Sobre estos ministros ver la citada obra de RODRIGUEZ CASADO, V., La política y los políticos ..., pp. 86-87 (Wall) y 93-94 (Grimaldi).

4. La correspondencia confidencial entre Tanucci, Wall y Grimaldi se encuentra en el Archivo General de Simancas (= AGS), Estado, legs. 6091 (1759), 6092 (1760-61), 6093 (1762), 6094 (1763), 6096 (1764), 6097 (1765), 6099 (1766), 6100 (1767), 6101 (1768), 6102 (1769), 6103 (1770), 6104 (1771), 6105 (1772), 6106 (1773), 6107 (1774), 6108 (1775) y 6109 (1776: final de la correspondencia porque tanto Grimaldi como Tanucci cesan en sus cargos de Primeros Secretarios de Estado). Copia de las cartas que Tanucci escribe a Wall y Grimaldi se halla en los libros copiadores de la correspondencia de Tanucci: AGS, Estado, libros 236 a 302.

5. AGS, Estado, leg. 6096: Grimaldi a Tanucci. San Ildefonso 7 agosto 1764.

6. Sobre estos aspectos ver el artículo de BARRIO GOZALO, M., «Política eclesiástica y religión a través de la correspondencia de Tanucci y Grimaldi a mediados del Setecientos», en Anthologica Annua, 40 (1993) 215-245.

7. En relación con este tema ver los trabajos de EGIDO, T., «El regalismo y las relaciones Iglesia-Estado en el siglo XVIII", en GARCÍA-VILLOSLADA, R., dir., Historia de la Iglesia Española, IV, Madrid 1979, pp. 125-249; e ID., «La religiosidad de los ilustrados», en Historia de España (Menèndez PidalJover), XXXI/1, Madrid 1987, pp. 395-435; MESTRE, A., Mayans y la España de la Ilustración, Madrid 1996, pp. 151-190; etc. 
En consecuencia, «la regalía, desde la mentalidad de sus propugnadores, no es una intromisión real en materias eclesiásticas, sino un derecho inherente a la Corona de regular, en virtud del propio poder real, determinadas materias eclesiásticas» ${ }^{8}$.

El monarca, por tanto, se convierte en poder supremo e interprete inapelable de sus competencias. Basta con aplicar el concepto de regalía a la amortización, al exequatur, al protectorado de la Iglesia, etc., como se hizo o intentó hacer, para que el ámbito de las competencias soberanas del monarca afecten no solo a las relaciones diplomáticas, sino a todas las manifestaciones de la Iglesia española, a la que se pretende «reformar» y hacer más nacional, luchando contra las injerencias de la curia romana. Pues, como decía Wall, «el mundo está ya muy ilustrado para no conocer la diferencia que debe haber entre lo temporal y lo espiritual, para no advertir los males que resultan a las naciones de esta confusion, y para consentir que con pretexto de la religión y de las preocupaciones del vulgo intente Roma sobre la regalía de los soberanos y la libertad de los pueblos lo que estamos viendo cada día".

Aunque la Iglesia no poseía juridicción alguna sobre las cosas temporales en cuanto tales, había muchos campos de jurisdicción mixta y su control era disputado en el siglo XVIII por la Iglesia y el Estado ${ }^{10}$.

La curia romana, apoyándose en las afirmaciones de teólogos y canonistas que seguían defendiendo algunos aspectos de la teoría medieval del poder directo del papado, había elaborado un cuerpo doctrinal cuya esencia se contenía en las falsas decretales de Isidorus Mercator, en las reservas pontificias, en las reglas de la Cancillería y en la bula In Coena Domini. En estos códigos se enunciaban explícitamente las regalías eclesiásticas, que deprimían la potestad real y exaltaban los derechos de los papas sobre el poder temporal de los reyes y, por tanto, chocaban con las regalías mayestáticas, pues los monarcas y ministros regalistas también trataban de ir controlando los campos imprecisos de la jurisdicción mixta.

En el siglo XVIII, el poder pontificio es atacado de forma sistemática por las monarquías católicas y los papas se ven precisados a otorgar algunas concesiones a los monarcas por medio de la firma de un concordato. Sin embargo, los príncipes no se contentan con estas concesiones y comienzan a reivindicar éstas y otras más como si fueran derechos inherentes a la Corona. En este sentido, toda la centuria sirvió de escenario al tira y afloja entre las concesiones de la curia romana y los presuntos derechos de los monarcas.

Además, la concepción del poder absoluto de los monarcas exigía, por razón de Estado, la absorción o eliminación, si era preciso, de aquellos grupos o instituciones que menoscabaran el libre ejercicio de su soberanía. De ahí el interés del Estado por neutralizar las posibles injerencias de la corte de Roma y su esfuerzo por ir nacionali-

8. DE LA HERA, A., El regalismo borbónico en su proyección indiana, Madrid 1963, p. 128; Id., «Notas para el estudio del regalismo español en el siglo XVIII", en Antario de Estudios Americanos, 31 (1974) 409-440. El mismo autor ofrece una síntesis de la evolución del regalismo en el Diccionario de Historia Eclesiástica de España, III, Madrid 1973, pp. 2066-2068.

9. AGS, Estado, leg. 6093: Wall a Tanucci. Buen Retiro 6 abril 1762.

10. Sobre este tema ver la interesante síntesis de OLAECHEA, R., «Relaciones entre la Iglesia y el Estado en el siglo XVIII», en ALBEROLA, A. y LA PARRA E. (eds.), La Ilustración española. Actas del Coloquio Internacional (Alicante, 1-4 octubre 1985), Alicante 1986, pp. 271-298, a quien sigo en estas líneas. 
zando la Iglesia a través de la regalía del patronato regio y la exaltación de la figura del obispo como bastión defensivo contra las usurpaciones de la curia romana.

Por tanto, uno de los cometidos de la política del Estado absolutista consistía en cerrar o controlar las diferentes vías de penetración que la corte romana utilizaba por medio de los nuncios apostólicos, los breves, bulas y demás documentos pontificios, y por la inmunidad de los eclesiásticos.

El Consejo real examinaba atentamente las credenciales que cada nuncio traía consigo, para ver si no vulneraba las regalías de la Corona, pues en caso contrario eran rechazadas y no se admitía al nuncio hasta tanto que Roma las rectificara.

Igual control se imponía a los documentos romanos que, por no referirse a cuestiones puramente dogmaticas o de penitenciaría, podían lesionar las regalías de la Corona. Esta forma de control se conocía como práctica del exequatur o pase regio, pues los documentos romanos no eran reconocidos oficialmente ni entraban en vigor hasta después de recibir el refrendo aprobatorio del exequatur.

Frente a la inmunidad de los eclesiásticos que, sin dejar de ser vasallos del soberano, gozaban del privilegio de fuero el gobierno adoptó una política de control y desgaste, máxime respecto a las órdenes religiosas llamadas exentas que, al depender directamente de la jurisdicción pontificia, estaban eximidas de la autoridad de los obispos.

Por otra parte, junto a la oposición al centralismo de la jurisdicción pontificia, el gobierno se preocupó de exaltar la figura del obispo como remedio contra las usurpaciones y gravámenes de la curia romana, pues al convertir al episcopado en un instrumento subordinado al poder estatal los monarcas podían incoporar a su ámbito algunos puntos de la jurisdicción mixta que estaban íntimamente mezclados con aspectos económicos, como sucedía con las dispensas. Se conforma así una corriente episcopalista que se pronuncia por un sitema de Iglesia de tipo constitucional y representativo, que rechaza el absolutismo papal y lo reduce a un simple «procuratore della Chiesa universale». Un episcopalismo, en fin, conjugado con el reconocimiento del primado pontificio y alentado por el afan de recuperar por parte de los obispos los derechos primitivos de la plena jurisdicción episcopal, «usurpados» por la codicia de la curia romana. Roma, dice Tanucci, ha querido en vano turbar el justo uso de la potestad episcopal, "ma essa fá sempre il suo gioco di ficcarsi in tutto e di non esser contenta dell'onor del Primato e abusar del Primato per spogliare tutti fratelli, quali ella stessa chiama li Vescovis".

De esta forma, el siglo XVIII se abre con el manifiesto episcopalista de Solis ${ }^{12}$, que recomienda a Felipe $\mathrm{V}$ que restablezca a los obispos hispanos en sus «derechos

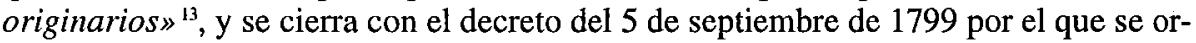

11. AGS, Estado, leg. 6069: Tanucci a Grimaldi. Portici 6 magio 1766.

12. Fue obispo de Lérida desde 1701 hasta 1714, en que promueve a Córdoba, donde muere el 14 de octubre de 1716. En 1713 fue presentado por Felipe V a Sigüenza, pero Roma no le confirmó. Más información en FERNÁNDEZ ALONSO, J., «Francisco de Solis, obispo intruso de Ávila (1709)», en Hispania Sacra, 13 (1960) 175-190.

13. «Dictamen que de orden del rey (...) dio el Ilmo. Sr. D. Fancisco Solís, obispo de Lérida y virrey de Aragón, en el año 1709, sobre los abusos de la corte romana por lo tocante a las regalías de S.M. Católica y jurisdicción que reside en los obispos», en VALLADARES, Semanario Erudito, IX, pp. 206-290. 
dena que los obispos españoles «usen de toda la plenitud de sus facultades (originarias), conforme a la antigua disciplina de la Iglesia, para dispénsas matrimoniales y demás que les competan ${ }^{14}$.

\section{LUCHA CONTRA LA «USURPADORA» ROMA}

El concordato de 1753 excusa a Madrid de las infinitas negociaciones, recursos y quejas que tanto trabajo dieron por espacio de trescientos años, pues Roma transfiere al monarca español y a sus sucesores el derecho universal de nombrar y presentar en todas las iglesias metropolitanas, catedrales, colegiatas y diócesis de los reinos de España a los sujetos que juzgase idóneos para ocupar los oficios y beneficios eclesiásticos seculares y regulares, con cura o sine cura, de cualquier naturaleza que sean, existentes al presente o que en adelante se fundasen. En consecuencia, el concordato suprimía las reservas pontificias relativas a la presentación y provisión de beneficios (arts. 13 y 14), y a la percepción de los frutos beneficiales (arts. 15 y 17-21) con el consiguiente golpe a las finanzas de la curia romana. Sin embargo, quedaban intactos los beneficios de patronato laical, las dispensas matrimoniales y las gracias de particulares, que debían seguir expidiéndose en la forma acostumbrada ${ }^{15}$. Por esta razón, Grimaldi podía decir a Tanucci con cierta satisfacción:

«Ya tenemos en nuestra mano toda la materia beneficial, que era el verdadero Po. tosí de Roma, pues aun para las dispensas en este asunto es necesario permiso de la Cámara, que concede rarísima vez. Quedan frailes, quedan dispensas para matrimonios y otras cosas de menor momento, que irán remediándose conforme los obispos vayan conociendo lo que pueden y conforme el rey vaya usando de su regalía suprema y de la calidad de protector y promotor de la verdadera disciplina eclesiástica» ${ }^{16}$.

A partir de la firma del concordato, la política eclesiástica española se mueve en torno a las dos clásicas reivindicaciones: control de la Iglesia española en los organismos e instituciones que pueden albergar posibilidades de acción antirregalista y, en relación con Roma, en completar lo que el concordato de 1753 había dejado pendiente ${ }^{17}$.

Pero todavía era mucho lo que faltaba por hacer, pues «Roma será siempre, si se lo consienten, lo que ha solicitado ser desde el tiempo de Gregorio VII y nunca lo fue en los primeros siglos» ${ }^{18}$. Por ello, se debía continuar mirando a la corte de Roma como a una enemiga solapada y escurridiza, pues iquién estaba seguro de que la curia romana, "al no poder conseguir sus deseos por medio de interpretaciones voluntarias, aceptaría a la larga los hechos sin negar la obligación de mantener y observar

14. OLAECHEA, R., El Cardenal Lorenzana en Italia (1797-1804), León 1980, pp. 226-234, precisa el contendio de este decreto; y SIERRA, L., El episcopado español ante el decreto de Urquijo, septiembre 1799, Madrid 1964.

15. DE LAMADRID, R.S., El concordato español de 1753, Jeréz de la Frontera 1937, pp. 132-145; MERCATI, A., Raccolta di concordati su materia ecclesiastica tra la Santa Sede e la Autorità Civile, I, Città del Vaticano 1954, pp. 422-437.

16. AGS, Estado, leg. 6100: Grimaldi a Tanucci. Madrid 30 junio 1767.

17. Amplia información en la obra de OLAECHEA, R., Las relaciones hispano-romanas en la segunda mitad del siglo XVIII. La Agencia de Preces, Zaragoza 1966, 2 vols.

18. AGS, Estado, leg. 6093: Wall a Tanucci. Buen Retiro 6 abril 1762. 
el concordato», fundándose en la regla curial de que los derechos de la Silla apostólica son inabdicables? ${ }^{19}$.

La imagen de Roma "usurpadora y dominadora» se va acentuando en la correspondencia de Tanucci desde finales de la década del cincuenta, en que se observa un reforzamiento del anticuarialismo, que bebe sus planteamientos más agresivos en el antijesuitismo ${ }^{20}$. El cambio aparece estrechamente ligado a la muerte de Benedicto XIV (1758) y a la elección de Clemente XIII, con el nombramiento del cardenal Torrigiani como Secretario de Estado ${ }^{21}$.

Torrigiani se muestra a los ojos de Tanucci y Wall como la bestia del Apocalipsis, que funda toda su gloria en burlarse de los soberanos a fin de mantener e incrementar la grandeza temporal de Roma, sin darse cuenta que el poder temporal de los papas tuvo su origen en la liberalidad y condescendencia de los soberanos, y que sólo puede subsistir a su abrigo ${ }^{22}$. Esta política, a juicio de Wall, causa mucho perjuicio a Roma "porque quanto más se opone a los soberanos en aquellas cosas razonables y factibles tanto es más regular que se les obligue a considerar lo que pueden por sí mismos y hacerse independientes de Roma en aquellos puntos temporales en que han querido depender por puro respeto y condescendencia, tal vez por ignorancia y más comúnmente por haber visto en los papas buena correspondencia y armonía» ${ }^{23}$.

La publicación del Catecismo del abate Mesenguy en Nápoles, apoyada por Tanucci ${ }^{24}$ y recibida con el «applauso di tutti li parochi e vescovi» del reino de las Dos Sicilias, y su posterior condena, «conseguida por los jesuitas a fuerza de intrigas y artificios» ${ }^{25}$, arrecia la polémica.

«Contra este libro -dice Wall- se ha declamado en Roma en los púlpitos, pero lo extraño es que preguntados los declamadores si lo habían leido respondian que no, que predica-

19. BN, ms. 11367: Dictamen del Sr. Roda sobre el Concordato de 1753. Lo citado en el $\mathrm{n}^{\circ} 9$.

20. Sobre estos puntos ver los trabajos de ONIS, P., «Bernardo Tanucci nel monto anticurialista del Settecento», in Nuova Rivista Storica, X (1926) 8-10; y ROSA, M., «Religione e politica ecclesiastica atraverso l'Epistolatio di Bernardo Tanucci», in Bernardo Tantucci e la Toscana, Firenze 1986, pp. 40-47. El antijesuitismo de Tanucci no implica una buena relación con los jansenistas como partido. De ellos escribe a Galiani este duro juicio: «Io non trovo i Giansenisti migliori dei Gesuiti; io li trovo egualmente bugiardi, calumniatori e sediziosi. Bisogna star securo di non cadere nei Giansenisti cacciando li Gesuiti» (AGS, Estado, libro 278, f. 259v: Napoli 5 agosto 1767). Lo que comparte con los jansenistas es su antipatía a Roma, tan propio de la época.

21. Luigi Torrigiani, creado cardenal por Benedicto XIV en 1753 y amigo de los jesuitas, fue nombrado secretario de Estado por Clemente XIII en octubre 1758. Ricardo Wall en carta a Roda (16-XI-1760) dice que «es de genio muy fuerte, si no fuera cardenal y sacerdote, diría insolente. No atiende que su ministerio principal es el de serlo del vicario de Cristo, se imagina serlo del rey de Prusia y obligaría al Papa a la guerra para defender derechos y posesiones». Cit. por DANVILA, M., Reinado de Carlos III, II, pp. 222-223.

22. AGS, Estado, leg. 6092: Tanucci a Wall. Napoli 6 gennaio 1761.

23. AGS, Estado, leg. 6092: Wall a Tanucci. El Pardo 27 enero 1761.

24. MAIORINI, G.M., «Bernardo Tanucci e il Catechismo de Mesenguy», in Storia e Politica, 16 (1977) 610-663.

25. En el Archivo Vaticano (= ASV), AN Madrid, vol. 108, hay abundante documentación sobre la prohibición de la Exposición de la Doctrina Cristiana o Catecismo del abate Mesenguy, con copias de los breves dirigidos al rey, a la reina y al confesor real; cartas del nuncio al obispo-gobernador del Consejo, a Ricardo Wall y al Inquisidor general, así como informes de Campomanes, del Consejo y de la Cámara de Santa Clara de Nápoles sobre la prohibición del libro en España y Nápoles. 
ban contra él porque el Papa, que tampoco lo había leido, decía que era un mal libro. Su Santidad se explicaba asi porque se lo había oido decir a Torrigiani, y éste que confesó también no haberlo leído, hablaba de él por lo que habia oído decir al General de los jesuitas» ${ }^{26}$.

Al mismo tiempo se generaliza la crítica contra los regulares,

"vero canchero del genere humano, presentemente ocupati di avarizia e di ozio e di burlare $i$ governi in tutto, come si fossero stabiliti nelle republiche per disfarle e opporsi alle lor leggi fondamentalis ${ }^{27}$,

se acentúan los juicios negativos sobre la política romana y se configura la concepción tanucciana sobre la degeneración de Roma, pues no la importa el evangelio, la religión o el bien de los estados, sólo pretende "poner bajo sus pies las soberanías y a los soberanos». Degeneración que más tarde Tanucci imputa sobre todo a los jesuitas, que aparecen a sus ojos como reos «di aver difesa Roma dopo che era stata (...) riformata; rei de averla armata con ridurre a sistema tutte le scellerate adulazioni dei teologi e dei canonisti antidiluviani», con el resultado de que el papado, "procuratore della Chiesa Universale», se haya convertido en el papado de Gregorio VII, de Inocencio III y de Julio II, estableciendo «el sistema di una religione e di un sacerdozio mondano, politico, lussurioso, pomposo, regio, tirannico» ${ }^{28}$.

Para sostener este despótico sistema Roma pone especial interés en confundir los límites entre la jurisdicción eclesiástica y civil, valiéndose para ello de la ignorancia que los eclesiásticos y el pueblo tienen de la historia de la Iglesia y de la verdadera ciencia canónica, pues los pocos libros que leen son de canonistas y de teólogos parciales y aduladores de la curia romana, ya que los que defienden las regalías del monarca, al estar prohibidos por Roma, son accesibles a muy pocas personas ${ }^{29}$. Como resultado de los falsos principios en que los eclesiásticos educan a la juventud y la falta de buenos libros, son muchos más los juristas que están imbuidos de las máximas romanas que de la defensa de las regalías del monarca ${ }^{30}$.

El único lenguaje que entiende Roma es el de los hechos consumados, por eso se alegra Tanucci cuando Carlos III establece el exequatur regium en noviembre de 1761, afirmando que el pase regio era el único medio que tenían los soberanos católicos para oponerse a la conducta de la corte de Roma, «que tenía cien ojos y cien manos para poner asechanzas a las regalias, usurpando la jurisdicción y el dinero" ${ }^{31}$.

Ante el establecimiento del exequatur ${ }^{32}$, que estaba en vigor en la mayoría de los estados católicos y ya se practicaba en gran parte de los dominios españoles, Roma

26. AGS, Estado, leg. 6092: Wall a Tanucci. Buen Retiro 24 marzo 1761.

27. AGS, Estado, libro 242, f. 128v: Tanucci a Bottari. Caserta 5 aprile 1760.

28. AGS, Estado, libro 278, f. 280r: Tanucci a Galiani. Napoli 8 agosto 1767.

29. OLAECHEA, R., «Relaciones entre Iglesia y Estado ...», pp. 275-281.

30. AGS, Estado, leg. 6092: Wall a Tanucci. Buen Retiro 17 noviembre 1761.

31. AGS, Estado, libro 252, f. 104r: Tanucci a Losada. Napoli 22 decembre 1761. Tanucci dice a Wall (AGS, Estado, leg. 6092: Napoli 16 febbraio 1762) que España ha sido demasiado indulgente con la corte romana, y Wall corrobora la afirmación (Ibidem. Wall a Tanucci. El Pardo 9 marzo 1762), diciendo que «por espacio de muchos años los frailes y los eclesiásticos han dado el tono y modo de pensar, y Roma se ha servido de ellos y de una piedad mal entendida, que por lo general ha reinado en la nación, para promover sus intereses y pretensiones, contrarias muchas de ellas a la regalía y derechos de los vasallos ...».

32. OLAECHEA, R., «El concepto del exequatur en Campomanes», en Miscelanea de Comillas, 45 (1966) 119-187. 
no se resigna. "Grita que está herida la libertad eclesiástica y la autoridad del Santo Padre», y afirma que se opone al artículo primero del Concordato de 1737 , lo que la exime de la obligación de observar el de 1753. Es decir, Roma reviste sus pretensiones temporales con aspectos puramente espirituales para intimidar y deslumbrar a los ignorantes, "haciendo servir la religión a la politica» ${ }^{33}$, y se esfuerza en hacer cumplir sólo aquello que beneficia sus intereses, despreocupándose de lo demás, como se puede observar en las disposiciones del Concilio de Trento. Cuanto allí se acordó favorable a la inmunidad y privilegios eclesiásticos, e incluso más, todo está en su mayor observancia; en cambio, los capítulos de reforma que tanto costó establecerlos se hallan tan olvidados que no se sabe que existen, y si algún monarca trata de hacerlos cumplir, Roma le acusa de cismático y le trata peor que a los herejes ${ }^{34}$.

Al comenzar el año 1763 Wall se muestra de acuerdo con Tanucci en que toda la problemática con Roma se refiere a «ochavos» y es de carácter jurisdiccional y no sacramental, y añade:

"¿Qué sería del poder, comodidad y lujo romano si se estableciese la autoridad de los obispos, si no se dieran en Roma dispensas o no se dieran por dinero; si los frailes y los monjes dependieran de sus Ordinarios; y por fin, si se borrasen de todos los libros ultramontanos los principios pecuniarios, de jurisdicción y de dependencia que ha sabido extender Roma al abrigo de la ignorancia y de máximas y artificios reprensibles? En sólo diez meses despues de establecido el exequatur en España se han presentado en el Consejo tantas dispensas matrimoniales, buletos de oratorios y de otras varias clases que asciende su importe, según un cálculo prudente que ha hecho el fiscal del Consejo, a medio millón de pesos. Una gran parte de estas dispensas han sido dadas contra lo prevenido en el Concilio de Trento, por cuya razón y por otras más consideraciones parece que ha pensado el Consejo en tratar seriamente la materia y en proponer al rey algunos medios para remediar tan grande abusos ${ }^{35}$.

La crítica de Tanucci y de Wall se radicaliza al observar el auri sacra fames que prima en la actitud de Roma ${ }^{36} \mathrm{y}$ «el temerario proyecto de sujetar a la jurisdicción inaginaria del Papa a todos los principes católicos, aniquilando toda potestad temporal o haciéndola al menos dependiente de la eclesiástica para enseñorearse de todo y atraer a Roma, con pretexto del bien espiritual, los tesoros de la cristiandad» ${ }^{37}$.

Los principios de desinterés, mansedumbre y obediencia que el Maestro imprimió a su Iglesia, los han sustituido los romanos por los de avaricia, altivez e independencia de "ésta que ellos llaman Iglesia y que con más propiedad debemos nosotros

33. AGS, Estado, leg. 6093: Wall a Tanucci. Buen Retiro 14 diceimbre 1762.

34. AGS, Estado, leg. 6094: Wall a Tanucci. Madrid 4 julio 1763.

35. AGS, Estado, leg. 6093: Wall a Tanucci. El Pardo 11 marzo 1763.

36. AGS, Estado, leg. 6093: Wall a Tanucci. Buen Retiro 28 diciembre 1762. «El origen de las desaveniencias de Roma con casi todos los soberanos -dice Wall a Tanucci- son el lujo, los palacios, las carrozas, la abundancia de criados, las magníficas casas de campo y, por fin, el hambre y ansia de dinero, que en aquella Corte eclesiástica puede llamarse auri sacra fame. Sin duda el origen de todas sus disputas y rompimientos son sobre asuntos que llevan el dinero a Roma, pues los dogmas puros de nuestra sacrosanta religión no pueden dar ocasión a disputas entre buenos católicos ni llevar a Roma dinero, y así se ve quan poco o nada iba de toda la cristiandad en los primeros siglos de la Iglesia y quan grande era entonces la sencillez y aun la pobreza de los papas y de todos los eclesiásticos».

37. AGS, Estado, leg. 6094: Wall a Tanucci. Buen Retiro 7 junio 1763. 
llamar escuela de interés y dominación». Y Ricardo Wall afirma, parafraseando a Tanucci, que en los siglos oscuros del medievo fueron los romanos poco a poco imponiendo a la cristiandad el pesado yugo que hoy sufre. Con el despertar de los tiempos modernos algunos pueblos quisieron librarse de tan pesada carga, pero Roma se resistió. Los que lo intentaron sólo pudieron conseguirlo rompiendo con el papado y ello abrió una llaga incurable en el corazón de los romanos, «no tanto por la separación de su creencia, por no ser esto lo que más les interesa, quanto por ver cerradas aquellas minas y despreciada su autoridad». Después de la Reforma los papas han procurado explotar con más intensidad a los pueblos que han permanecido en su obediencia, para resarcirse así de lo que perdieron con los que se.separaron ${ }^{38}$.

La retirada de Wall del ministerio y el nombramiento de Grimaldi en septiembre de 1763 hace temer a Tanucci que el nuevo ministro se deje invadir del fanatismo español por la corte de Roma,

«la quale vuole che il mondo creda una cosa medesima: Religione Cattolica e Corte de Roma; cioè, porvertà e ricchezza, non Regno di questo mondo e Regno di questo mondo, obbedire ai Magistrati e ai Sobrani e non obbedire, ma comandare ai Magistrati e ai Sobrani con molte altre contraddizioni simili a questo» ${ }^{39}$.

Pero no fue así, y Grimaldi tranquiliza a Tanucci diciéndole que el cambio de ministerio no supone mutación alguna en la política con Roma ${ }^{40}$.

El nuevo ministro es más flexible pero no menos regalista que Wall y, de inmediato, se incorpora a la lucha contra la corte de Roma, para que restituya "lo que injustamente les ha usurpado», con la esperanza de ver «el momento feliz de que la parte católica de la Europa rompa la cadena con que por tantos años se ha visto oprimida de la ignorancias ${ }^{41}$.

Tanucci, nostálgico de la antigua disciplina de la Iglesia, sigue criticando con dureza a la curia romana por haber usurpado a los obispos sus poderes con el fin de ejercer un control absoluto sobre la Iglesia y el pueblo, y así aumentar su poder y riqueza, de tal manera que «tutto è in essa Roma carne e sangue, gesuiti, denaro, Dataria, Segreteria dei Brevi e oltre simili bottegue pecuniarie» ${ }^{42}$. Grimaldi va más lejos y afirma que no comprende la pasividad que los principes católicos tienen con Roma, a pesar de la esclavitud en que mantiene a sus pueblos, hasta el punto que los reinos se hallan más o menos florecientes o miserables según estén más o menos adheridos a la corte de Roma ${ }^{43}$. Lo único que importa a las autoridades romanas es la Curia,

"perche porta denaro e giurisdizione esterna e contenziosa, la quale divien denaro e autoritá profana sulle cose temporali» ${ }^{44}$.

En cambio, se despreocupan de las cosas netamente espirituales, como son la administración de los sacramentos, la predicación y la disciplina en las costumbres y en los ritos, que es de lo que se tendrían que preocupar.

38. AGS, Estado, leg. 6094: Wall a Tanucci. Buen Retiro 26 abril 1763.

39. AGS, Estado, libro 265, f. 54r: Tanucci a Squillace. Napoli 31 gennaio 1764.

40. AGS, Estado, leg. 6096: Grimaldi a Tanucci. Aranjuez 15 marzo 1764.

41. Ibidem.

42. AGS, Estado, libro 265, f. 282v: Tanucci a Fogliani, Napoli 21 aprile 1764.

43. AGS, Estado, leg. 6096: Grimaldi a Tanucci. San Ildefonso 25 septiembre 1764.

44. AGS, Estado, libro 266, f. 213r: Tanucci a Grimaldi. Portici 10 luglio 1764. 
Los medios que utiliza Roma para mantener e incrementar su poder son fundamentalmente la política que practica en el nombramiento de los obispos y de otros beneficios eclesiásticos, los regulares, las dispensas y otros muchos recursos.

Es verdad que en España no existe el problema del nombramiento de obispos, porque todos eran de nominación real desde el año 1523, al igual que sucedía con la casi totalidad de los restantes beneficios eclesiásticos desde el concordato de 1753 , pero Roma había conseguido limitar la jurisdicción episcopal para incrementar su poder.

La jurisdicción de los obispos, a juicio de Tanucci, proviene directamente de Jesucristo cuando dijo a los apóstoles «mitto vos sicut missit me Pater, quorum remiseritis peccata remituntur eis, et quorum...», pero Roma ha usurpado la potestad episcopal porque

"essa fà sempre il suo gioco di ficcarsi in tutto e di non esser contenta dell'onor del Primato e abusar del Primato per spogliare tutti fratelli, quali essa stessa chiama li Vescovi, ed ha tenuto di mutare l'antica formula e denominazione che pur tropo dimostra quel primus inter pares che la Chiesa tutta Cattolica, eccettuati li moderni pochi adulatori di Roma, ha reputato e reputa il Papa» ${ }^{45}$.

Grimaldi se muestra de acuerdo con las afimaciones de Tanucci, pero añade que la mayor parte de los obispos se encuentra muy conforme con la «degradación» a que les ha reducido Roma y los escritores que la apoyan, pues «por lo regular cuando son mozos no estudian más libros que los que deprimen la potestad episcopal, y así cuando viejos obran y opinan según estos principios, aunque sea en detrimento suyo» ${ }^{46}$.

Las ideas episcopalistas de éstos y otros políticos regalistas no son algo extraño, sino que reflejan el sentir general de los defensores del regalismo en el siglo XVIII, que propugnan la jurisdicción episcopal «jure divino», con merma de la jurisdicción del papado, pues el dogma del primado no estada todavía definido ni tampoco existían unos principios doctrinales que precisaran las relaciones del episcopado con el papado, delimitando sus respectivas competencias, y mantuvieran el difícil equilibrio entre ambas jurisdicciones. Por ello Tanucci repetirá hasta la saciedad que «il Primato è onore e situazione, non potestà intrinseca de diverso genere», ya que de acuerdo con la doctrina de los Santo Padres es difícil encontrar alguna cosa que el obispo no pueda hacer y el papa si, fuera de la convocatoria del concilio general ${ }^{47}$.

Es verdad que, mientras para algunos ilustrados, como Mayans, el obispo Climent, etc., la defensa de la jurisdicción episcopal era un instrumento de reforma eclesiástica $^{48}$, para la mayoría de los políticos el episcopalismo era un instrumento para controlar la Iglesia nacional y un arma contra la curia romana.

Otro de los tentáculos de la corte de Roma son los regulares, que actúan como una especie de quinta columna.

"Los frailes -dice Grimaldi- no tienen patria. Desde el momento en que profesan se deben mirar como extranjeros, sino como enemigos del Estado donde nacieron. Es una

45. AGS, Estado, libro 273, f. 284v: Tanucci a Grimaldi. Porfici 6 maggio 1766.

46. AGS, Estado, leg.6099: Grimaldi a Tanucci. Aranjuez 28 mayo 1766.

47. AGS, Estado, libro 273, f. 284v: Tanucci a Grimaldi. Portici 6 magio 1766.

48. LLIDO, J., «Filojansenismo y regalismo en la España de Carlos III, según los documentos inéditos del Archivo General de Simancas», en Anales Valentinos, 4 (1978) 356-359. 
milicia en la que los Papas han hallado el secreto de mantener a costa de los mismos pueblos a quienes les hacen la guerra. Ni son españoles, napolitanos ni franceses, son romanos donde quiera que se hallen. La Europa Católica ha estado ciega muchos siglos dejando propagar sin medida este carcoma que la roe interiormente, y quizá quando quiera moderarlo no ha de poder conseguirlo» ${ }^{49}$.

Por ello, Tanucci defiende la necesidad del exequatur para los documentos que provenían de los superiores religiosos que habitaban fuera del reino y Grimaldi clama contra esta milicia papal, pidiendo la "nacionalización» de todas las órdenes regulares, no solo para afirmar la preeminencia regia sino también para evitar la importante transferencia de rentas hacia las casas matrices del exterior ${ }^{50}$. Es más, mientras que los ilustrados se conforman con "reformar» a la mayoría de los regulares ${ }^{51}$, en el caso de los jesuitas optan por su expulsión y posterior extinción, porque la Compañía representa la encarnación del espíritu que los reformadores combaten en la Iglesia, pues no sólo es una orden exenta sino también defensora del papado y baluarte ideológico de la curia romana ${ }^{52}$.

Por otra parte, Roma a través de las dispensas, la concesión de indulgencias, privilegios y exenciones, y de la interpretación de las desgracias como un castigo de Dios, había ido formando un entramado socio-religioso que la daba un inmenso poder. Es decir, «Roma gioca a favor suo tutte le carte, le morti, li desgrazie. Tutti li mali che sono purtroppo comuni e quotidiani a tutto il genere umano attribuisce essa a qualche cosa che sia fatta a sua istanza» ${ }^{53}$.

Si a todo esto se suman los clérigos seculares que esperan obtener alguna prebenda de Roma, los padres que intentan conseguir algún beneficio o pensión eclesiástica para sus hijos, los terciarios de las órdenes religiosas y los «ignoranti facili a sedursi», se comprenderá fácilmente que Roma creyera «di aver nelle Corti molte vie» para imponer su poder.

A pesar de que ya en 1762 Carlos III había dicho a Tanucci que en las relaciones con Roma «no echemos más carne al fuego y esperemos que Dios nos ayudará en esto para que todo se componga como se debe y yo deseo ${ }^{54}$, y Grimaldi le recuerde en 1764 que "el tiempo no es favorable para oponerse a los abusos que la corte de Roma ha introducido, va introduciendo cada día y mantiene en los estados católicos» ${ }^{55}$, Tanucci no puede callar ante las «usurpaciones romanas» y contesta con estas interesantes palabras:

49. AGS, Estado, leg. 6096: Grimaldi a Tanucci. San Ildefonso 26 agosto 1764.

50. Para paliar el problema de la dependencia romana de los exentos el gobierno procuró que se eligiera como general de las grandes órdenes religiosas a un español o a un vicario general español para la provincia española, cuando el general no fuera hispano.

51. CORTES PEÑA, A.L., La política religiosa de Carlos III y las órdenes mendicantes, Granada 1989; y CARO LÓPEZ, C., «La reducción de las órdenes regulares. Documentos para un caso de la política religiosa en tiempos de Carlos III», en Hispania Sacra, 44 (1992) 335-392.

52. BATLLORI, M., «La expulsión de los jesuitas y el jurisdiccionalismo antirromano: raíces napolitanas y austriacas", en Carlos III y' la llustración, I, Madrid 1988, pp. 235-245.

53. AGS, Estado, libro 266, f. 106r: Tanucci a Grimaldi. Caserta 5 giugno 1764.

54. AGS, Estado, libro 323, f. 81r: Carlos III a Tanucci. San Ildefonso 21 septiembre 1762.

55. AGS, Estado, leg. 6094: Grimaldi a Tanucci. San Ildefonso 11 septiembre 1764. 
«Io, che sono tanto vechio, devo più di ogni altro far profitto di questo avvertimento de V.E., vedendo che a mio tempo non può venire quel sereno e quel sole che illumini le tenebre dei popoli, e li persuada a fissarsi e ricerver la regola e il precetto Evangelico di dar a Dio e al Sovrano quel che si deve. A Dio si deve tutto, anche quel che si deve al Sovrano. Vicari di Dio son li Sovrani, egualmente che li sacerdoti colli vescovi, loro capi, e col Papa, primo dei vescovi e primo de tutta la Chiesa; e li Sovrani e li vescovi sono stati fatti da Dio. Dio stesso ce lo insegnato e li suoi apostoli, e ce lo ha dato per dogma di fede. Io dunque, in questa mia gravissima età devo lasciare ai giovani questo pensiero e questa speranza» ${ }^{56}$.

Pero no bastan las bellas palabras, hay que actuar para poner freno a las usurpaciones romanas, con la esperanza de que "Dio faccia venire il giorno della luce e della libertà per le Corti e nazioni cattoliche dagli artighi dei cortigiani di Roma, fabbricati nei secoli tenebrosi» ${ }^{57}$. Para que esta esperanza se haga realidad, a juicio de Tanucci, no hay otra vía que la convocatoria de un concilio, máxime ante las favorables circunstancias de que "due terzi dei cattolici sono sudditi dell'Augustissima Casa Borbone, e delll'altro terzo una buona parte è dell'ora amica e alleata Corte di Vienna» ${ }^{58}$. Grimaldi se muestra más «ilustrado» y afirma que el mejor medio para llevar a cabo la reforma es culturizar al pueblo, de tal manera que "se contentaría con dejar a Roma con sus estafas y su dinero, siempre que sus máximas y su influjo no entretuvieran tanta superstición y tanta ignorancia en los pueblos que la reconocen por cabeza. Déme V.E. -dice a Tanucci-estudios, déme instrucción y la reforma vendrá ella misma por sus pasos» ${ }^{59}$.

El tiempo iba pasando y Tanucci no podía «soffrire l'abominavole artifizio della Corte di Roma», pero seguía esperando «il giorno della luce e della libertà».

\section{A MODO DE CONCLUSIÓN}

Al finalizar el pontificado de Clemente XIII la lucha contra la curia romana apenas había dado frutos y la imagen de la nueva Iglesia diseñada por los ilustrados seguía siendo sólo un bello proyecto.

La curia romana dirigida por el cardenal Torrigiani, «que se considera Visir despótico de un monarca superior a todos los príncipes del universo», sigue actuando con altanería y tratando a los príncipes como simples vasallos ${ }^{60}$, como hace con el duque de Parma y la publicación del famoso Monitorio, al que Grimaldi califica de un «atentado tan horrendo» que obliga a Carlos III a oponerse a las ideas de Roma, no sólo para librar al Infante, su sobrino, de la opresión en que intenta ponerle la Curia sino también porque su causa afecta a todos los soberanos católicos ${ }^{61}$.

Esta actitud despótica y depredadora de la corte de Roma provoca la indignación de la Casa de Borbón, afirmando que no «sufrirán semejantes arrojos contra las más

56. AGS, Estado, libro 267, f. 250v: Tanucci a Grimaldi. Portici 2 ottobre 1764.

57. AGS, Estado, libro 266, f. 107r: Tanucci a Grimaldi. Caserta 5 giugnio 1764.

58. Ibídem.

59. AGS, Estado, leg. 6095: Grimaldi a Tanucci. San Ildefonso 7 agosto 1764.

60. AGS, Estado, leg. 6101: Grimaldi a Tanucci. Madrid 29 marzo 1768.

61. AGS, Estado, leg. 6101: Grimaldi a Tanucci. El Pardo 23 febrero 1768. 
sentadas regalías de los soberanos y contra sus tribunales y ministros», a la vez que se ordena recoger el Monitorio y cualquier otro "papelote» que se publique en Roma o venga de aquella Corte y que pueda ofender la regalía o providencias del gobierno, o turbar la quietud pública ${ }^{62}$. Al mismo tiempo se traza un plan para forzar a Roma a retirar el Monitorio, amenazando con la ocupación de Benevento y Avignon ${ }^{63}$.

Tanucci, más radical y mejor conocedor de la curia romana, piensa que la ocupación de Avignon y de Benevento no bastará para pesuadir a la corte de Roma,

"che è una colluvie di forestieri che vanno a profittarsi dei beni ecclesiastici di tutta l'Italia, e del denero delle spedizioni e delle dispense di tutto il cattolicismo, e delle tantte cause ecclesiatiche che con tanto artifizio vi si tiranno" ${ }^{64}$,

y afirma que es preciso que la ocupación de estas ciudades vaya acompañada de la suspensión de las expedicciones y de otras resoluciones que sean conformes a la verdadera disciplina de la Iglesia y a la práctica de los doce primeros siglos. Conviene restituir a los obispos su jurisdicción y someter a los frailes y monjes a la obediencia de superiores nacionales, pues con estas medidas los curiales romanos se verán privados de gran parte del dinero y pedirán al papa que cambie de política ${ }^{65}$.

De momento la Curia no tiene en cuenta las amenazas y hace creer «al infeliz viejo [Clemente XIII] que todo el mundo y particularmente España está en visperas de alzarse a favor de la Iglesia, que juzga oprimida». Estas noticias hacen pensar a Grimaldi que «han perdido ya el poco seso que les quedaba» ${ }^{66}$, pues si los curiales juzgan que hay alguna razón para temer al pueblo y a los eclesiásticos se engañan totalmente, ya que si no se toman represalias lo deben agradecer a la piedad y moderación del monarca, «no a escrúpulos necios ni a ideas pusilánimes como ellos con insolencia y desvergonzadamente publican ${ }^{67}$.

El cerco contra la intransigencia romana y contra los jesuitas, sus mentores, se va cerrando. Para presionar la negociación y conseguir la revocación del Monitorio, Nápoles se apodera de Benevento y Pontecorbo, y Francia de Avignon. Portugal se une a los borbones para pedir la extinción de los jesuitas y, poco después, lo hace Viena ${ }^{68}$. Incluso se plantea la invasión de los estados de Castro y Ronciglione, pues los representantes de las cortes borbónicas en Roma piensan que el medio más eficaz para hacer cambiar de opinión a Roma es privarla de los cien mil escudos que producen estos estados ${ }^{69}$.

Ante la terquedad de Roma, que insinúa que el Monitorio era irrevocable, las cortes católicas afianzan sus regalías, niegan el poder temporal de los papas y amenazan a Clemente XIII con tomar represalias. Carlos III restablece la pragmática del

62. AGS, Estado, leg. 6101: Grimaldi a Tanucci. El Pardo 22 marzo 1768.

63. AGS, Estado, leg. 6101: Grimaldi a Tanucci. El Pardo 1 marzo 1768.

64. AGS, Estado, leg. 6101: Tanucci a Grimaldi. Portici 19 aprile 1768.

65. Ibidem.

66. AGS, Estado, leg. 6101: Grimaldi a Tanucci. Aranjuez 18 abril 1768.

67. AGS, Estado, leg, 6101: Grimaldi a Tanucci. Aranjuez 13 junio 1768.

68. Ibidem.

69. AGS, Estado, leg. 6101: Grimaldi a Tanucci. Madrid 28 junio y 12 julio 1768. 
exequatur ${ }^{70}$, manda recoger la bula In Coena Domini ${ }^{71}$ y en unión con otros gobiernos exige la extinción de la Compañía de Jesús.

La muerte repentina de Clemente XIII el 2 de febrero de 1769 deja a la Iglesia en una situación de enfrentamiento con los estados católicos, pero la elección de Clemente XIV el 19 de mayo de 1769 alumbra de nuevo la esperanza de que es posible destruir el «abominavole artifizio della Corte di Roma» para que brille «il giorno della la luce e della libertá».

70. Novísima Recopilación ..., libro II, tít. 3, ley 9. La pragmática que establecía el exequatur regium en España fue recogida por real decreto de 5 de julio de 1763 y restablecida por otro de 16 de julio de 1768.

71. LÓPEZ, J.L., Historia de la bula In Coena Domini, Madrid 1768. Fue abolida en 1770 por el papa Clemente XIV. 